\title{
Urban Growth, Liveability and Quality Urban Design: Questions about the efficacy of urban planning systems in Auckland, New Zealand
}

\author{
*Dr.LEE BEATTIE', Dr.ERROL HAARHOFF² \\ 1 \&2 School of Architecture and Planning, University of Auckland, Auckland, New Zealand \\ E mail: l.beattie@auckland.ac.nz, E mail: e.haarhoff@auckland.ac.nz
}

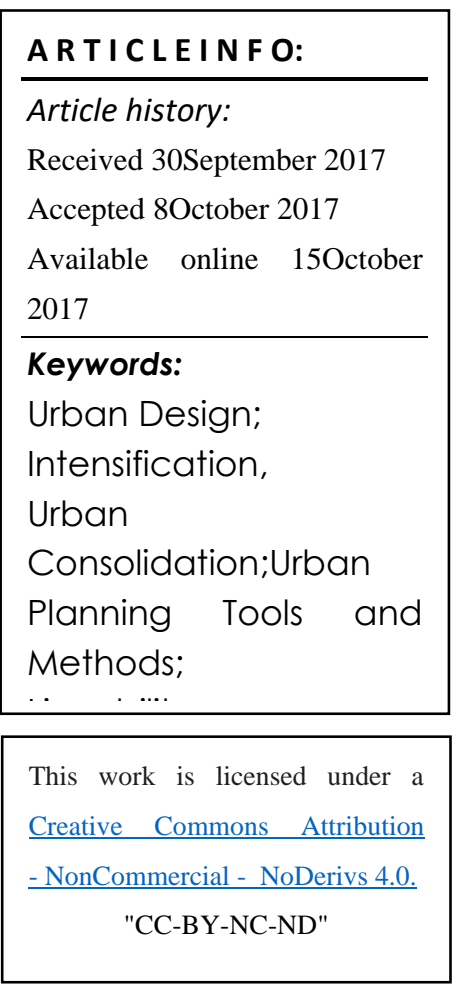

\begin{abstract}
A B S T R A C T
Preventing sprawl and concentrating future urban growth at transit centres, typifies many urban planning strategies in a number of Australian, New Zealand and North America cities. Newer iterations of these strategies also argue that compact development delivers public benefits by enhancing urban 'liveability' through good urban design outcomes. Where neoliberal economic conditions prevail, achieving these aims is largely dependent on market-driven development actions requiring the appropriate urban planning responses to ensure these outcomes. However, there are growing concerns that urban planning approaches currently used are not effectively delivering the quality urban design outcomes expected and enhancing residents' liveability. This paper reports on an evaluation of three medium density housing developments located in areas designated for intensification in Auckland, New Zealand. Examined is the extent to which the development outcomes are aligned with the statutory urban planning requirements for quality urban design. The results indicated contradictions and points to limitations of the statutory planning system to positively influence quality outcomes, leading to enhanced residents' experiences.

JOURNAL OF CONTEMPORARY URBAN AFFAIRS (2018) 2(2), 12-23.

https://doi.org/10.25034/ijcua.2018.3667
\end{abstract}

www.ijcua.com

Copyright (C) 2017 Journal Of Contemporary Urban Affairs. All rights reserved.

\section{Introduction}

Among others, an important goal of urban planning is directing future development towards outcomes that will deliver enhanced social, environmental, cultural and economic benefits. A number of urban planning approaches that restricted urban sprawl were thus initially promoted on the argument that this would preserve the natural environment and rural character surrounding cities as a necessary amenity for urban dwellers (Ingram, et al, 2009; Haarhoff, et al, 2012). The higher density development that is a consequence of containing urban growth within an urban boundary was subsequently justified by evidence that a more compact urban form reduces fossil fuel consumption and noxious emissions, and leads to enhanced sustainability (Newman and Kenworthy, 1989; 1999).

\section{*Corresponding Author:}

University of Auckland, Auckland, New Zealand

E-mail address: I.beattie@auckland.ac.nz 
Characterised by Quastel et al (2012) in their study of Vancouver as 'sustainability as density', the outcome is also argued to deliver benefits to urban dwellers.

These arguments are key to underpinning urban growth management plans in many cities across Australia, New Zealand and North America including the cities of Auckland, Melbourne, Brisbane, Portland and Vancouver (cf. Auckland Council, 2012; Department of Transport, Planning and Local Infrastructure, 2002; Department of Infrastructure and Planning, 2009; Metro Portland, 2012; Nikoofam, \& Mobaraki(2016) ;Metro Vancouver, 2010). They all establish urban growth boundaries to contain urban sprawl, and concentrate the greater part of future development to designated areas within walking distances of public transport, as transit-oriented development (TOD's). These transit centres (activity centres in Australia, town/metropolitan centres in Auckland, station communities in Portland) as points of concentration also play a role by providing local employment, services and a range of retail and public amenities. The concentration of future development in, and around, transit centres requires the deployment of multi-unit housing typologies to achieve the higher densities, contrasting with lower density detached housing that has, and indeed still does, dominate most cities in these countries. This intention to concentrate growth is made explicit in the Victoria State government's growth plan for metropolitan Melbourne where it is seen as '... the lynch-pins of a multi-centred structure ...where people can enjoy the benefits of living closer to work with less congestion on the roads and public transport networks' (Department of Transport, Planning and Local Infrastructure, 2010, p. 5). There is now sufficient evidence to demonstrate that these policies are being successful in terms of increasing the number and proportion of higher density, multi-unit housing options in Australian and New Zealand cities (Bunker et al, 2002; Buxton and Tieman, 2005; Randolph, 2006; CHRANZ, 2011). Indeed, in Australian cities this change is seen by Randolph as 'a revolution' where 'little over a generation ago living in flats (apartments) was a minority pastime' (2006, p. 473).

Despite this apparent success in delivering higher density options, critics argue that this is not necessarily delivering fully on the aims of the associated urban growth management plans for a number of reasons. This include resistance to living at, and with, higher density, market reluctance to invest in the higher density housing typologies, and argument that this form of urban growth management negatively impacts housing affordability (Haarhoff et al, 2012). A newer area of critique suggests that the urban planning system and current approaches themselves may be faulty. For example, despite urban growth management plans requiring concentration of new development at activity centres, there is evidence of slippage in meeting this goal (Bunker et al, 2002; Buxon and Tieman, 2004; 2005; Woodcock et al, 2011 ; Haarhoff et al, 2012). Phan et al. (2009), in their study of the spatial distribution of new residential construction between 2001-2006 in the City of Clayton in the Melbourne metropolitan region, found that the goal of directing development to activity centres has not yet been achieved. Much of the residential development occurred as urban sprawl beyond an 800-metre walking distance of activity centres. For Melbourne as a whole, Woodcock et al. argue that 'seven years into the implementation of Melbourne 2030 ... not only has there been very little intensification of activity centres in established suburbs, but there have been few urban design visions that might engage the public imagination or that of the development industry' (2011, p. 95). Indeed, they assert that higher density housing is being approved 'almost anywhere' despite concentration being mandated within walking distances of 'activity' centres (Woodcock et al, $2011)$.

This suggests a weakness in the urban planning system to fully deliver outcomes that are well aligned with the urban growth management plans. This point is also made by the Victoria State government's own 2007 audit of Melbourne 2030,that found a lack of specific urban planning tools to direct development into the designated 'activity centres' (Woodcock et al, 2011 ). On this issue, Buxton and Tieman (2005) suggest that the "urban consolidation of Melbourne 2030 will be undermined where there is policy confusion involving some signals which seek urban consolidation and other signals which allow urban dispersal' (Buxton and Tieman, 2005, p.155).

These assessments are related to a perceived failure on the part of the relevant urban planning systems to comprehensively direct new development towards areas within walking distances of designated activity centres. In part, shortcomings also result from a failure to provide the infrastructure on which transit-oriented development depends, especially on the urban peripheries (Buxton \& Tieman, 2005; Jain and Courvisanon, 2008). To add to these issues, more 
recent iterations of urban growth management strategies have raised expectations further. To counter arguments that higher density development negatively impacts on the urban experience, more recent iterations of urban growth plans are justified on the grounds that quality urban design inherently enhances urban 'liveability' (Haarhoff et al, 2012, and 2016). Such goals are expressed in the UK Government's strategy for improving place quality in declaring that 'good quality place should not be seen as a luxury but a vital element in our drive to make Britain a safer, healthier, prosperous, more inclusive and sustainable place' (UK Government, 2009, p. 2). The idea that development focused on the primacy of street life, a sense of urbanity, walkable neighbourhoods, and connected communities promotes urban 'lliveability' is well argued in current practices (Calthorp, 1993; Ditmar and Ohland, 2004; Condon, 2010;Arenibafo, 2016 Campoli, 2012).

The emphasis on 'liveability' also underpins calls for the replication of 'traditional' town forms in which these urban qualities are embedded, particularly in the practice of New Urbanism (Barnett, 2003). Critics of this approach have questioned whether such traditional qualities can be achieved solely through design actions and manifestos (Dixon and Dupuis, 2003), and doubts can be raised about whether manifestations of New Urbanism in the form of gated communities result in the urban public life envisaged. Despite these doubts, The Auckland Plan, is Auckland non-statutory spatial plan is promoted as a strategy to 'create the world's most liveable city' (Auckland Council, 2012), and to promote:

'more compact neighbourhoods, supported by quality networked infrastructure offers opportunities to create healthy, stimulating and beautiful urban environments...that enhance social cohesion and interaction by attracting people...to a mix of cafes, restaurants, shops, services and well design public spaces' (2012, p. 42).

This paper adds to a small but growing number of studies reporting on efficacy of the urban planning systems to deliver outcomes well aligned to aims of the urban growth management plans. This paper questions the ability of urban planning methods and tools to deliver the enhanced liveability and quality urban design outcomes being promoted in recent iterations of urban growth management plans. Any failure to deliver the quality urban design promised not only potentially brings disappointment to city residents, but might also bring into question the efficacy of this form of urban growth management.The effective implementation of urban growth strategies requires alignment with the local statutory land use plans, and the support of the local authorities who are normally responsible for implementing the higher order policy directives (Beattie and Haarhoff, 2014; Waldner, 2008). This requires the local statutory plans to have the appropriate urban planning and design policy responses, and the right mix of statutory tools and methods to achieve the quality urban design outcomes sought. The New Zealand urban planning system, not unlike those found in Australia, Canada and United States, uses a rational conformance based approach that links the local statutory plan (district plans) to intended policy outcomes to the built outcomes (Beattie, 2013; Laurian et al, 2010; Ericksen et al, 2003). Based on land use zoning designations, these methods usually take the form of zone codes setting out permitted uses supported by a range of performance-based rules. These include controls over building height set back from boundaries, that development proposals are required to meet. In this way, the district plan provides a range of methods for district plan users and developers to follow, which if adhered to, should achieve the intended policy outcomes in the in the physical development (Beattie, 2013; Ericksen et al, 2003).

The paper aims to test the extent to which the application of high-level policies for urban intensification are effectively applied at the local level to positively influence development towards good urban design outcomes. This is assessed through three case studies of medium density housing development located in two suburban town/metropolitan centres in Auckland designated for higher density development in the Auckland Plan and Auckland's statutory land use plan adopted in 2017; the Auckland Unitary Plan (Auckland Council, 2012 and 2016). Auckland is New Zealand's largest city, containing a third of the national population and is facing significant growth pressure. Current predictions estimate that the current population of 1.5 million will increase a further 1 million by 2030 (New Zealand Government, 2010; Auckland Council, 2016).

It should also be noted that in 2010, new unitary governance arrangements were establishment for the Auckland region. The new Auckland Council replaced a regional authority and seven previous local authorities that had responsibility for a range of urban planning functions in their districts. The case study locations of Albany and Onehunga were previously under the jurisdiction 
of the North Shore City Council and the Auckland City Council (1999) respectively. Planning consent for the case study developments reported in this paper predate the release of the Auckland Plan and the newly adopted Unitary Plan. However, the previous local authorities statutory district plans were all aligned to the 2005 Auckland Regional Policy Statement (ARPS) adopted by the now disestablished Auckland Regional Council (ARC), that followed the same policy direction towards urban intensification as expressed in both the Auckland and Unitary Plans. The ARC was legally required to provide a regional and strategic planning overview to local authorities, including urban growth management issues that the local authorities were required to give effect to through their district plans. This enables the three case studies to be assessed against an earlier regional policy (the ARPS) and the two-relevant district plans under the jurisdiction of the previous local authorities that specifically sought to translate the higher-order policies into good urban design outcomes through the development process.

\section{Research Design and Methodology}

A four-phase mixed research design was employed using quantitative and qualitative assessment techniques to examine the three case study developments. The first phase sought to determine the relevant policy outcomes for medium density housing from each of the relevant district plans to consider whether the policy responses were aligned with the strategic regional policy direction in the ARPS. This was achieved by examining the district plan objectives and policies, and comparing these with the district plan's stated expected results (Environment Results Expected). This follows the policy outcome mapping technique developed by Beattie (2013), building on the Laurian et al (2010) and Ericksen et al (2003) approach to plan quality and evaluation. The second phase examined the relevant district plan's methods and tools, including the zoning codes and performance standards designed to achieve the district plan's urban design policy goals. The third phase involved an independent assessment of the developments using urban design best practice criteria established by the Ministry for the Environment (MFE) and published in their guide: Medium-Density Housing: Case Study Assessment Methodology (Ministry for the Environment, 2012). Using the MFE guide enabled a consistent and comparable assessment to be undertaken of all three case studies in their neighbourhood contexts, the elements of which are set out in Table 1.

Table 1.Urban design assessment criteria

Source: Ministry for the Environment's Medium-Density Housing: Case Study Assessment Methodology (2012)

\begin{tabular}{|l|l|}
\hline Key urban design areas & Sub element \\
\hline Site context and layout & Neighbourhood context \\
\cline { 2 - 2 } & Site context \\
\cline { 2 - 2 } & Landscape coverage \\
\cline { 2 - 2 } Building form and & Outdoor living spaces \\
\cline { 2 - 2 } & Car parking and access \\
\cline { 2 - 2 } & Service areas and utilities \\
\cline { 2 - 2 } & Horizontal modulation \\
\cline { 2 - 2 } & Continuous building line \\
\hline & Building roofline \\
\cline { 2 - 2 } & Façade articulation \\
\cline { 2 - 2 } & Material use and quality \\
\hline Street scene & $\begin{array}{l}\text { Street edge continuity and } \\
\text { enclosure }\end{array}$ \\
\cline { 2 - 2 } & Building entrances \\
\cline { 2 - 2 } & Façade opening \\
\cline { 2 - 2 } & Street boundary treatment \\
\hline Internal configuration & Internal / external relationships \\
\cline { 2 - 2 } & Visual privacy \\
\cline { 2 - 2 } & Aspect / natural ventilation \\
\hline
\end{tabular}

The final phase involved interviewing 8 of the previous local authority's urban planning officers who processed the resource consent applications for the three case study developments. The interviews followed the nonstandardised approach outlined by Davidson and Tolich (2003, p240). This approach allowed for semi-structured, open-ended questions where we guided the interviewees into the relevant areas related to the research to gain their perspectives. The questions covered their role the in resource consent process; their understanding of the relevant district plan's policy intention for urban design outcomes; whether the district plan provided clear methods for achieving those policy goals; whether the final outcomes represent a good urban design solution for the site; whether the development integrates into the local context, and whether there were any other factors in the district plan process which may have contributed to the actual development outcome. The interviews were carried out at a place of the interviewees choosing, lasting between 45 to 60 minutes, audio recorded under (protocols approved by the University of Auckland Human Ethics Committee), and transcribed by a third party. The interview transcriptions were analysed using narrative analysis to discover the key emerging themes (Wiles et al 2005). 


\section{Case study locations and context}

Medium density housing case study developments were selected that were within suburban areas designated for density intensification in the Auckland Plan (called 'areas of change') and within the previous relevant district plans and ARPS (Auckland Council, 2012 and 2016). Two case studies are located in the Albany town centre 17 kilometres north of the Auckland's CBD, and one in the Onehunga town centre 12 kilometres south of the CBD (see figure 1).

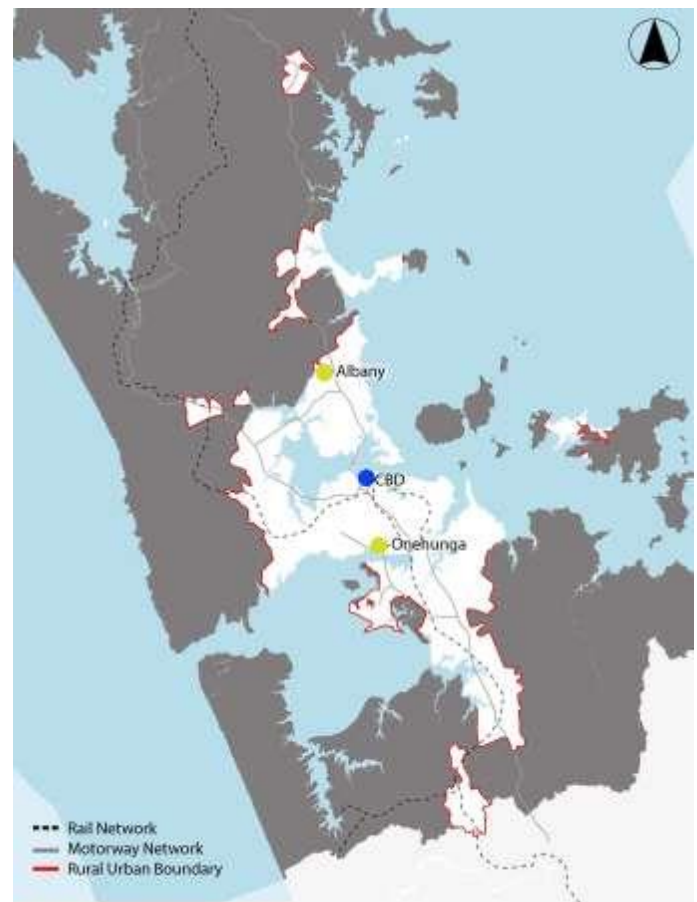

Figure 1.Auckland urban region showing the CBD (blue), and in red, Albany to the North and Onehunga to the south.

Now designated as a metropolitan centre, Albany has attracted considerable public infrastructure investment from both the previous North Shore City Council and the New Zealand government as a regional centre on Auckland's North Shore (Haarhoff et al, 2012). The area is dominated by a large shopping centre surrounded by other 'big-box' retailers and car parking, where most land currently remains vacant. Albany is served by a rapid bus service to central Auckland via a local bus station, largely operating as a park-and-ride facility. The two medium density case studies developments (The Ridge and Spencer Road) are within 800 metres of the bus station and shopping centre. Figure 2 show the location of the two-case study development in the Albany context, and 800 metre walking distance circles.

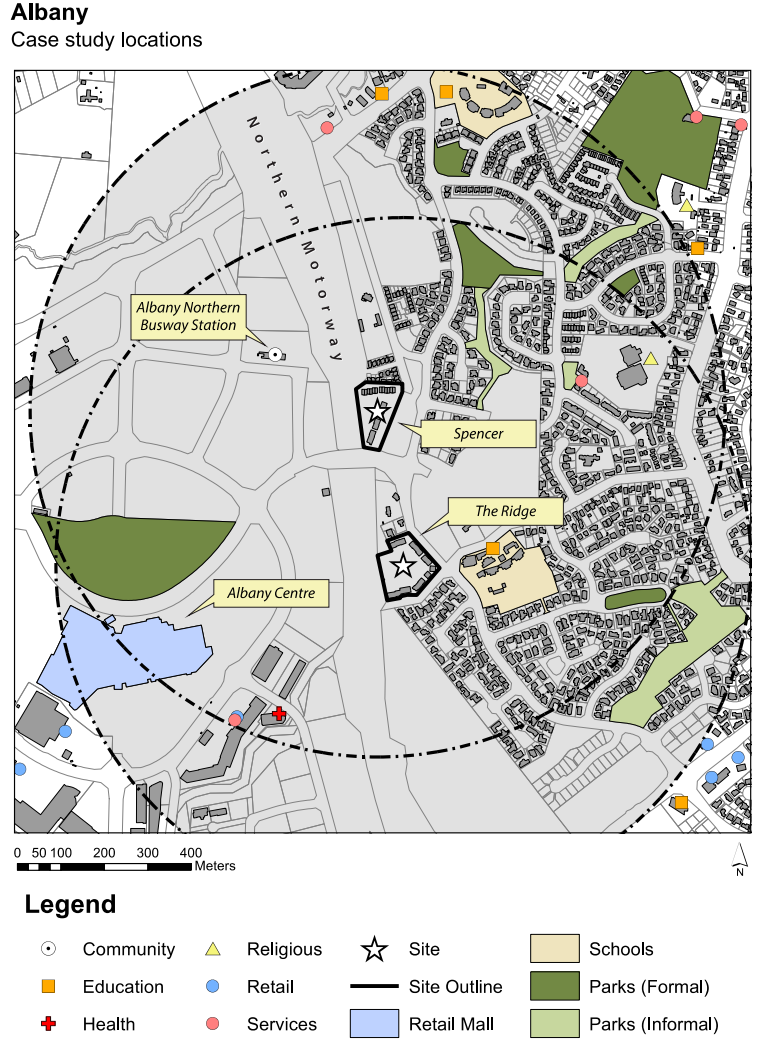

Figure 2.Albany case study development locations.

The area to the east of the case studies is dominated by detached housing, although zoning permits multi-unit housing. Both case study developments were zoned Area D: Varied Residential under the North Shore City district plan, which provides for a range of housing typologies subject to an urban planning and design assessment, that includes a range of performance standards such as density, building height and car parking. Built between 2005 and 2007, the developments together have 169 units at a net density of 67 units per hectare. The single level, two-bedroom units each with a floor area of $49.5 \mathrm{~m} 2$ are contained in a series of identical three storeys blocks (figure 3 ).

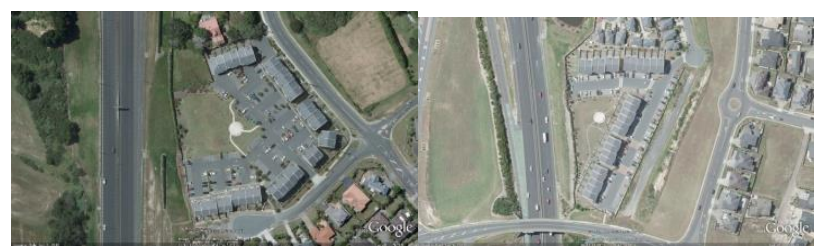

Figure 3. 'The Ridge' development (Left) and the 'Spencer' (Right) (Source: Google Earth, 2016)

Onehunga is one of Auckland's oldest and most established suburban town centres designated for intensified development with the adoption of the first regional planning document in 1974 (Auckland Regional Council, 1999). The Auckland Plan is consistent with the earlier district plans and identifies Onehunga as an 'area of 
change' able accommodate an additional 3,400 residential units and 5,500 new jobs by 2040 (Auckland Council, 2012). The town centre has a terminal railway station that links to Auckland's CBD, and is earmarked for extension to Auckland airport. The town centre offers a wide range of retail outlets, restaurants and public services and facilities such as parks and a library, and unlike Albany, Onehunga is pedestrian oriented. The case study development (Atrium on Main) is located to the north of the main shopping street, within easy walking distance of the railway station and bus connections (figure 4).

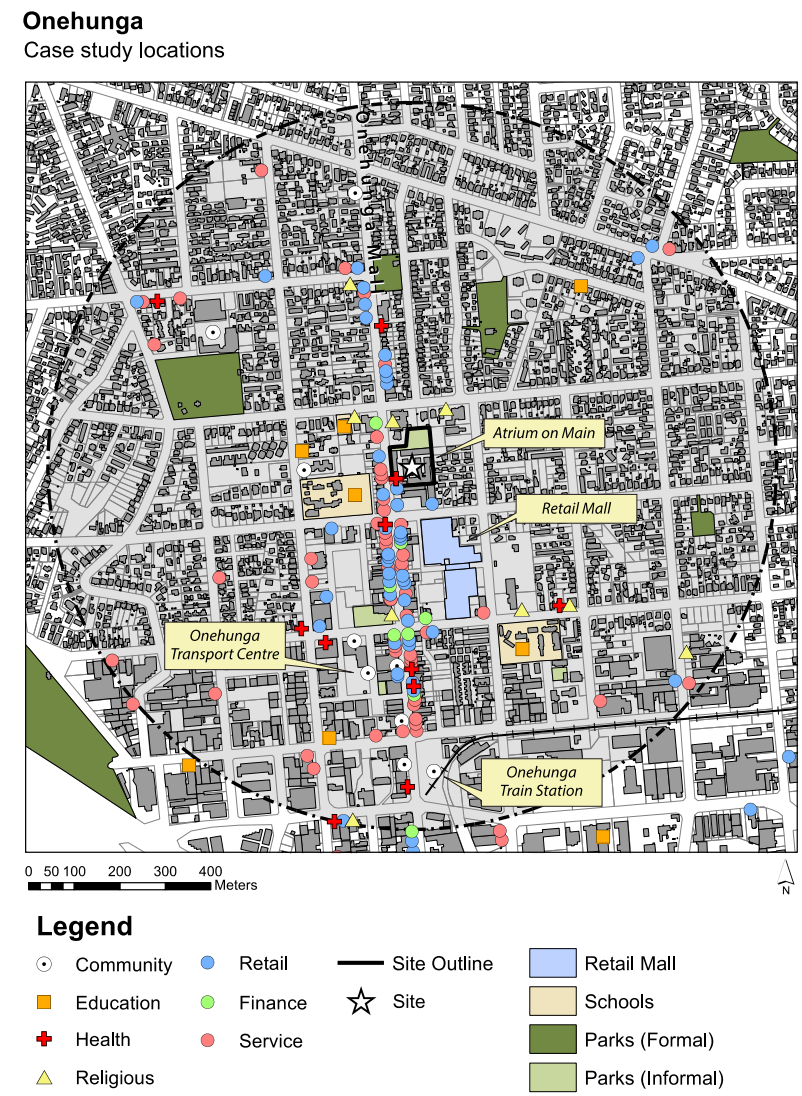

Figure 4. Auckland urban region showing the $\mathrm{CBD}$ (blue), and in red, Albany to the North and Onehunga to the south.

The case study developments comprise 112 residential units arranged in a perimeter block with a net density of 64 units per hectare, with units ranging in size from one to three bedrooms. There are also a few retail units at ground floor level facing the high street. The site is zoned Business 2 in the district plan and provides for a range of land use activities, including residential usage, subject to compliance with performance standards such as building height and car parking controls. An aerial view of the development is shown in figure 5 .

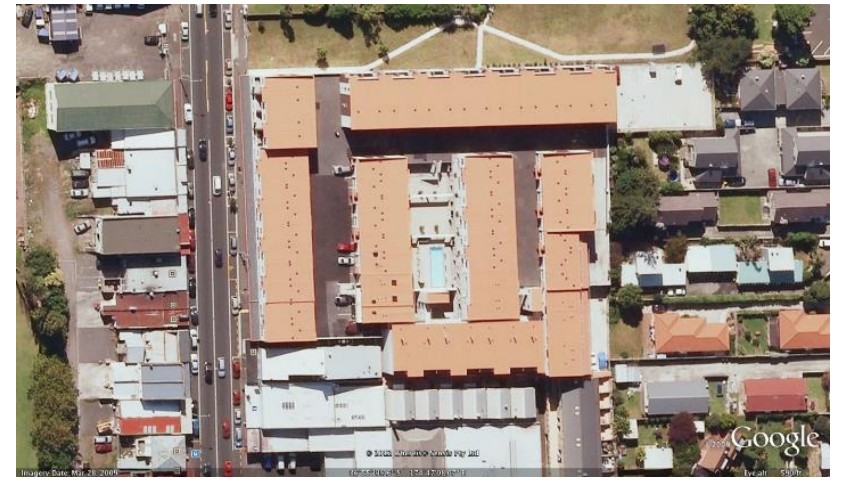

Figure 5. Aerial view of the Onehunga case study development.

\section{Results: Albany Case Studies}

It was difficult to define with any degree of certainty a clear policy picture from the North Shore district plan over its intended urban design policy outcomes for medium density housing. The policy direction given in the actual wording of the objectives and policies were judged to be unclear, poorly written and at times contradictory in different parts of the district plan. For example, conflicts exist between the transportation, residential and urban design sections of the district plan. Nonetheless, it appears at the strategic level that the North Shore district plan sought to facilitate the development of high-quality urban design. The relevant objective was to:

'effectively manage growth and change by achieving the maintenance and enhancement of a high quality built environment and enabling a wide choice of lifestyles, a range of types and affordability of housing and choice of employment opportunities by enabling development opportunities in and around subregional centres which demonstrates a high standard of design' (North Shore City Council, 2003, p 8).

This was supported by the Varied Residential zoning code's residential amenity objective seeking 'to ensure a high level of residential amenity by ensuring that layout and design achieves a high standard of security, visual and aural privacy and usable public and private open space' (North Shore City Council, 2003, p. 11). While it was difficult to gain a clear picture of the intended policy outcomes in the district plan for medium density housing, using these key objectives, it followed that the case-study developments should have been built to a highquality design standard, especially in areas within 800 metres of the metropolitan centre. This interpretation was confirmed by the urban planning officers interviewed.

The Resource Management Act (RMA), New Zealand's urban planning legislation, is based on 
a rational conformance approach where the district plan provides for a range of statutory methods and tools to achieve quality development outcomes through the development process. Thus, the relevant district plan included site density control (one residential unit per $150 \mathrm{~m} 2$ of site area), parking requirements (two car parking spaces per unit over $50 \mathrm{~m} 2$, or one if less), a maximum building height, and requirements for shared outdoor recreational areas within the development (North Shore City Council, 2003, pp. 30-33). While this provides potential developers with a guide to determine the residential unit yield, there was no control over residential type mix or unit size. The development was subject to resource consent where the application was assessed against these requirements and meeting quality urban design outcomes (North Shore City Council, 2003, pp. 16-83).

The independent assessment undertaken by the authors of these developments using the urban design criteria from table 1, indicated poor responses to all four areas: context and layout, form and appearance, street scene and internal configuration. Negative elements include the smallness of the two bedroom units $(49.5 \mathrm{~m} 2)$, poorly designed private open spaces, the domination of the internal courtyard by hardpaved parking and poorly located and designed shared spaces (figure 6). While the developments have some good points, including the solid construction and good street edge definition, these factors did not compensate for the other deficiencies. Perhaps the greatest deficiency in terms of meeting intended urban planning and design policy outcomes, was the poor pedestrian connection to the Albany town centre, and in particular, the rapid bus station, and thus not meeting policy requirements for quality developments within walking distances of transit centres.

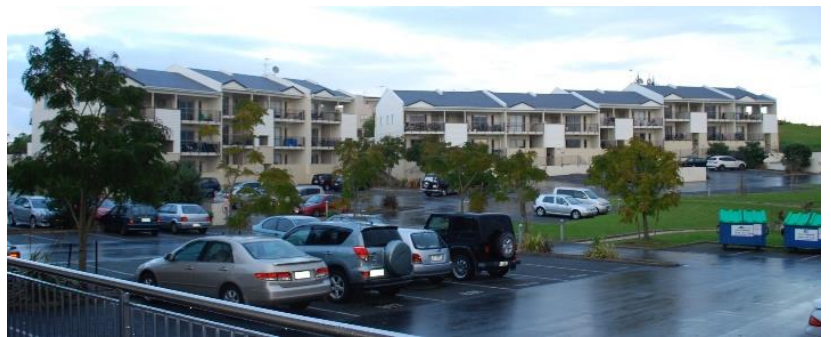

Figure 6.Internal view of the Albany case study development. The photograph shows the extent of surface car parking and poorly positioned waste disposal facilities (source: authors).

From interviews with relevant council urban planning officers, it became apparent that the small size of the residential units was a direct result of the district plan requirement for residential unit over $50 \mathrm{~m} 2$ to be provided with at least two car parking spaces. This, coupled with the Council's traffic engineering advice seeking at least 0.5 visitor car parking spaces per residential unit, became, in the interviewees' opinions, one of the major determining design factors. Also, all respondents felt that the district plan had weak intended policy outcomes and methods that diluted their ability to achieve good built form outcomes through the consenting process.

Another strong theme that emerged from the interviews was the district plan's density control method and its influence on the design process. All were of the opinion that the applicant simply divided the gross site area by $150 \mathrm{~m} 2$ to produce the housing yield for the sites without considering other factors that may have led to a better design resolution. In their views, this approach is not uncommon, especially where district plans provide density standards for residential development. Consequently, it appears that car parking and the site density controls were the two major determining design factors for the developments, which contradicted the intended urban design policy outcomes described in the district plan. This is somewhat concerning given policies promoting more compact development and reduced car dependency, and the newer imperatives to deliver 'liveability' and quality urban design.

\section{Results: Onehunga Case Study}

Using the policy intended outcome technique, it was almost impossible to get a clear picture of the relevant district plan's intended policy outcomes for medium-density housing for the Onehunga case study. The Business 2 Zone on which this development occurs provided objectives and policies for business use and associated activities, but no policy direction for residential activity or any other non-business activity. However, there were regulatory rules that controlled residential development within the zone, including a requirement for approval of a resource consent (planning permission). It is unclear how this approach was achieved through the plan making process, as it is contrary to the RMA's rational conformance based urban planning approach, where the plan methods (rules) are designed to give effect to the district plan's policy intention. This situation left the district plan without any policy guidance to direct district plan users or the council staff administrating the district plan on how to address residential uses within the business zone.

While there were no policy intentions given, the district plan did provide a range of statutory rules 
addressing residential development, including vehicle access and car parking controls (two per residential unit), a maximum building height of 12 metres and visual privacy controls to prevent residential unit outlook impacting adversely on neighbours (Auckland City Council 1999, p. 8). However, there was no residential density control limiting the number of residential units that could be developed on the site, nor restrictions on the residential mix or unit size.

The assessment of this development using the urban design criteria from table 1, was good on three of the criteria, namely, context and layout, form and appearance, and street scene. Internal configuration was judged to be poor. This assessment reflected on the following key characteristics: favourable location within the town centre; safe and easy access to public transport and a wide range of local and commercial services and facilities; and the perimeter block form is well conceived by creating a well-defined and potentially active street edge. Deficiencies related to the configuration arise from the insertion of additional units within the inner courtyard area that restrict internal outlook and result in narrow spaces between blocks, and the presence of driveways to lockup garages at the upper courtyard level that precludes better use.

Given this good assessed outcome, it was surprising to discover from the interviews that the relevant district plan did not express any urban design outcomes for medium intensity housing within the Business 2 Zone. The council urban planning officers were effectively left make their own professional judgements. Moreover, the better outcomes when compared to Albany, were achieved in spite of the fact that the relevant district plan provided little or no policy guidance. Consequently, the district had little impact on the actual design. This contrasts with Albany where more stringent rules and policy guides in fact led to a poorer outcome.

\section{Conclusions and Discussion}

Under the current neo-liberal economic context prevalent in New Zealand and elsewhere, quality urban place and space sought through development actions depends to a large extent on market investment with commercial goals (Goodman and Moloney, 2011). While acknowledging the potential contradiction between market-led goals in land development and the provision of quality urban space as a social benefit, Adams and Tiesdell (2013, p. 6) suggest that there is a potential alternative in what they call 'plan-shaped' markets. This defines a crucial role for urban planners and designers (and the urban planning process) as key mediators between market-driven imperatives and the delivery of public benefits through land development. Given the concern expressed about the weaknesses in the urban planning system from other research cited, and the outcomes to the research reported in this paper, delivering on the aspiration for good urban design will in part depend on effective urban planning tools and methods raising questions about the overall effectiveness of these approaches used.

In the context of cities that have rational conformance-based planning approaches, such as New Zealand, Australia and parts of North America, implementation of the regional strategies requires strong alignment with the local statutory land use plans and tools. These need to have appropriate policy responses, with the right mix of tools and methods to achieve the quality urban design outcomes sought. This paper has evaluated three medium density case study developments at two suburban locations in Auckland to assess this efficacy of the urban planning system to deliver quality urban design outcomes through the development process.

The independent assessment of the urban design qualities of the case study developments produced different, if not contradictory, results. In the Albany case studies, the development was judged to be poor on all of the urban design criteria used: context, building form and appearance, street scene and internal configuration. Yet the relevant district plan had clear policy tools and methods intended to direct good urban design outcomes, also well aligned with the regional strategy.

In the Onehunga case study, the development was assessed to be good in relation to three urban design criteria: context, building form and street scene, with shortcomings associated with the internal configurations. Notwithstanding the shortcomings, this development was assessed to be far better than the Albany developments. Yet in Onehunga, there is an absence of clear urban planning tools and methods specifically for residential development in what is a business zone: quality development notwithstanding of an absence of effective urban planning directives? Here the outcomes appear to have been largely the result of good discretionary decisions made by the responsible urban planning officers through the consenting process, in conjunction with good design on the part of the design professionals. Consequently, it is concluded that the relevant district plans and their tools and methods, have had limited impact on influencing and directing the 
development outcome of the three case studies, despite the implicit intentions that this should be so.

This conclusion raises a number of observations and questions. While limited, it parallels questions being asked about the efficacy of urban planning systems and processes in Australian cities cited in this paper, concerning the perceived misalignment between actual development and urban planning directives to concentrate growth and development at transit centres (Woodcock et al, 2011). The results from this research show that for the three case studies, the relevant urban planning tools and methods currently deployed in Auckland appeared to have had little or no impact on the delivery of good urban design outcomes that the higher order regional policies seek. Accepting that the scope of this study is limited, nevertheless, along with other studies cited on this question, it does point to a potential problem for achieving the strategic policy goals of enhanced liveability. For this reason, there is concern about the current newly adopted unitary plan for Auckland. The unitary plan, having both regional and local urban planning functions, through its zoning proposal and associated rules and guides is intended to give effect to policies for quality intensified development set out as goals in the Auckland Plan (Auckland Council, 2013). The question asked is whether this new plan has sufficiently addressed perceived shortcomings in the existing district plans that it will replace? For example, will it address problems identified by urban planners interviewed that the existing district plans are considered to be too broad, loosely written, unquantifiable with a disconnection between the weak policy direction and the zoning code and rules.

The more positive outcome in the Onehunga development case study also raises questions about the need for any urban planning directives at all, given the absence of any specific urban planning tools and methods for residential development in this example? The good outcome seems to have been derived from both good design and good judgements made by the council urban planning officers through the consenting process. There is little doubt that good quality development relies to a large extent on good quality design and designers - the urban planners, urban designers, architects and other built environment professionals involved, especially where serving market-driven development imperatives. However, this works best on larger sites where there is an opportunity to plan and design more comprehensively (CABE, 2008; Adams \& Tiesdell, 2013). To some extent, the kind of land development envisaged in the intensification of development around transit centres is predicated on the existence of large blocks of land or 'brownfield' sites opportunities. A good exemplar is a master-planned development on the urban periphery of Melbourne, at University Hill, in the City of Whittlesea. Here a large vacant site was master-planned to accommodate a mix of medium density housing, retail, commercial and light industrial activities, set in a welldesigned public realm. The result has won awards for the excellent urban design, and the success attributed to an enlightened developer willing to take risks on the urban periphery, a cooperative local authority willing to bend planning rules to achieve strategic aims and quality outcomes, and skilled urban planners, urban designers and architects (Beattie and Haarhoff, 2014). There are many other examples of successful masterplanned developments where the effective stakeholders cooperation and focuss on shared goals achieves successful urban design outcomes.

However, land suitable for large-scale development of this kind is limited in most cities, including Auckland where areas in the vicinity of many suburban transit centres are located. Delivering on the goals for intensified development and quality urban design across most metropolitan regions relies on smaller scaled, site-by-site development opportunities spread across metropolitan regions. Moreover, smaller scale, incremental developments in these contexts do not necessarily involve the range of highly skilled built environment professional's more likely deployed in master planned developments. Nevertheless, it is in such areas and contexts that a greater number of future developments can be expected, and where the relevant urban planning methods and tools need to be far more effective to ensure quality urban design outcomes.

Meeting the goals for good urban design outcomes, urban 'liveability' and the necessary concentration of higher density development are largely dependent on the development process through the market, mediated by the urban planning system. In the case studies reported, the urban design outcome is shown to be both good and poor, and that the planning methods and tools themselves had little impact on this outcome. In the context of smaller scale, incremental development at higher density applied across the larger part of metropolitan regions, this shortcoming is a serious concern. 
This study raises questions about the effective influence that statutory plans have had on achieving the desired quality urban design outcomes for the case studies at two suburban town centres in Auckland. This in turn raises more serious questions for implementation of the Auckland Council's new unitary plan, which also seeks to consolidate urban growth at such centres spread across the metropolitan region. Moreover, seen in the context of research in other cities where inefficiencies have been shown as obstacles to achieving the goals of urban intensification, there is sufficient reason to have more general concern on this issue. This paper is limited in scope to one city and three case studies. Nevertheless, it is argued that evaluating the effectiveness of the urban planning system to successfully deliver quality urban design outcomes that result in enhanced urban liveability and the associated social benefits, largely through market-driven land development processes, is a research area deserving more attention.

The opinions expressed and conclusions reached in this paper however are entirely those of the authors and do not necessarily reflect those of the funders nor persons interviewed.

\section{Acknowledgments}

This research did not receive any specific grant from funding agencies in the public, commercial, or non-for-profit sectors

\section{References}

Adams, D. and Tiesdell, S. (2013) Shaping Places: Urban Planning, Design and Development. London: Routledge. Availible at: http://eprints.gla.ac.uk/42615/

Auckland City Council (1999) Auckland City Council District Plan: Isthmus Plan section. Auckland: Auckland City Council. Availibe at: https://www.aucklandcouncil.govt.nz/plansprojects-policies-reports-bylaws/our-plansstrategies/district-and-regional-plans/districtplans/isthmus-district-plan/Pages/default.aspx

Auckland Council. (2012) The Auckland Spatial Plan.

http://www.aucklandcouncil.govt.nz/EN/plans policiesprojects/plansstrategies/theaucklandpl an/Pages/theaucklandplan.aspx , accessed 14 August 2014.

Auckland Council. (2016) The Unitary Plan., http://www.aucklandcouncil.govt.nz/EN/plans policiesprojects/plansstrategies/unitaryplan/Pa ges/unitaryplanoperative.aspx , accessed 14 August 2017.

Auckland Council (2013) Special Housing Areas: The Criteria.
http://www.aucklandcouncil.govt.nz/EN/ratesbuil dingproperty/housingsupply/Documents/shacri teria.pdf, accessed 21 August 2014.

Auckland Regional Council (1999), Auckland Regional Growth Forum: a vision for managing growth in the Auckland Region. Auckland: Auckland Regional Council. Available at: http://www.safekids.nz/Informationresearch/Information-SearchResults/Type/View/ID/7759

Auckland Regional Council. (2008) Proposed Plan Change 6 to the Auckland Regional Policy Statement. Auckland: Auckland Regional Council.

https://www.aucklandcouncil.govt.nz/plansprojects-policies-reports-bylaws/our-plansstrategies/unitary-plan/auckland-unitary-planmodifications/proposed-planchanges/docspc7/section-32-evaluation.pdf

Auckland Unitary Plan, Independent Hearings Panel. (2014), About US. http://www.aupihp.govt.nz, accessed 5 June 2014.

Arenibafo, F. (2016). The Transformation of Aesthetics in Architecture from Traditional to Modern Architecture: A case study of the Yoruba (southwestern) region of Nigeria. Contemporary Urban Affairs (JCUA), 1(1), 3544. https://doi.org/10.25034/1761.1(1)35-44

Barnett, J. (2003) Redesigning cities: principles, practices and implementation. Chicago: Planners Press. https://www.researchgate.net/publication/235 357552_Redesigning_Cities_Principles_Practice Implementation

Beattie, L. and Haarhoff (2014), E. Delivering quality urban consolidation on the urban fringe: A case study of University Hill, Melbourne, Australia. Journal of Urban Regeneration and Renewal 7(4): 329-342. Available at: https://www.researchgate.net/publication/277 612232_Delivering_quality_urban_consolidation on the _urban_fringe_A_case_study_of_Univer sity_Hill Melbourne_Australia

Beattie, L. (2013) Evaluating District Plan in Auckland, New Zealand: Do they deliver their intended outcomes. PhD thesis, University of Auckland, Auckland, New Zealand. Available at:

http://www.creative.auckland.ac.nz/people/lbeattie

Beattie, L. (2011) The Auckland Spatial Plan: the challenge of implementation. Paper presented at the 4th World Planning School Congress; Perth,

Australia. https://researchspace.auckland.ac.nz/handle/ 2292/16789 
Beattie, L. and Haarhoff, E. (2011) Governance: how to achieve urban growth management in practice: a practitioner perspective. Paper presented at the International New Urbanism and Smart Growth Conference; Perth, Australia.

https://researchspace.auckland.ac.nz/handle/ 2292/16669

Bunker, R., Gleeson, B., Holloway, D. and Randolph, B. (2002) The local Impacts of Urban Consolidation in Sydney. Urban Policy and Research, 20(2): 143-167. https://doi.org/10.1080/08111140220144461

Buxton, M. and Tieman, G. (2005) Patterns of Urban Consolidation in Melbourne: Planning Policy and the Growth of Medium Density Housing. Urban Policy and Research, 23:2: 137157. https://doi.org/10.1080/08111470500135086

CABE (2008), Creating successful masterplans, London: Commission for Architecture and the Built Environment. http://webarchive.nationalarchives.gov.uk/201 $10118095356 /$ http:/www.cabe.org.uk/files/crea ting-successful-masterplans.pdf , accessed 14 August 2014.

Campoli (2012), J. Made for Walking: Density and Neighborhood Form. Cambridge, MA: Lincoln Institute of Land Policy. https://www.google.com/urlesa=t\&rct=i\&q=\&e src $=s \&$ source $=w e b \& c d=1 \& c a d=r j a \& v a c t=8 \& v$ ed=2ahUKEwiygZ3y2avfAhXiioKHfCGBO4QFjAAegQICRAC\&url=https\%3A\%2 F\%2Fwww.coliman.org\%2Fapp\%2Fdownload\%2 F755906227\%2FwalkingCities.pdf\&usg=AOVVa w26jinJLdjASIGWbN_ixwsi

CHRANZ .(2011). Improving the Design, Quality and Affordability of Residential Intensification in New Zealand. Auckland: Centre for Housing Research Aotearoa New Zealand. https://www.smartgrowthbop.org.nz/media/14 11/g-improving-the-design-quality-affordabilityresidential-intensification.pdf

Department of Infrastructure and Planning (2009) South East Queensland Regional Plan 20092031.

http://www.dsdip.qld.gov.au/resources/plan/s eq/regional-plan-2009/seq-regional-plan2009.pdf, accessed 14 August 2014.

Department of Planning and Community Development (2010) Activity Centres Toolkit: Making it Happen. http://www.google.co.nz/\#q=victoria+state+a ctivity+centre+toolk accessed 14 August 2-14.

Department of Transport, Planning and Local Infrastructure (2002) Melbourne 2030: Planning for Sustainable

Growth. http://www.dpcd.vic.gov.au/planning/plansa ndpolicies/planningformelbourne/planninghist ory/melbourne2030, accessed 14 August 2014.

Dixon, J. and Dupuis, A. (2003) Urban Intensification in Auckland, New Zealand: a challenge for new urbanism. Housing Studies 18(3): 353-369. https://doi.org/10.1080/02673030304239

Ericksen, N., Berke, P., Crawford, J. and Dixon, J. (2003) Planning for Sustainability: New Zealand under the RMA. Waikato: International Global Change

https://www.amazon.com/Planning-

Sustainability-New-Zealand-

Under/dp/0473098148

Haarhoff, E., Beattie, L., Dixon, J., Dupuis, A., Lysnar, P. and Murphy, L. (2012) Future Intensive: Insights for Auckland's Housing. Auckland: The University of Auckland/Transforming Cities. https://researchspace.auckland.ac.nz/handle/ 2292/22332

Haarhoff, E., Beattie, L., \& Dupuis, A. (2016). "Does higher density housing enhance liveability? Case studies of housing intensification in Auckland". Cogent Social Sciences, 2(1). https://doi.org/10.1080/2331 1886.2016.1243289

Haarhoff, E. and Beattie, L. (2011). Questions about smart growth: a critical appraisal of urban growth strategies in three North American cities. Paper presented at the International New Urbanism and Smart Growth Conference; Perth, Australia. https://researchspace.auckland.ac.nz/handle/ 2292/16788

28Ingram, G., Carbonnell, A., Hong, Y-H and

Flint, A. (2009) Smart Growth Policies: an

Evlauation of Programs and Outcomes.

Cambridge, MA: Lincoln Institute of Land

Policy.

https://www.researchgate.net/publication/261 961928_Smart_Growth_Policies_An_Evaluation of_Programs_and_Outcomes_by_Gregory_K_In gram_Armando_Carbonell_Yu-

Hung_Hong_Anthony_Flint

Jain, A. and Courvisanon, J. (2008). Urban Growth on the periphery: ad hoc policy visions and research neglect. Paper presented at the 32nd ANZRSAI Conference; Adelaide, Australia. https://papers.ssrn.com/sol3/papers.cfm?abstr act_id $=2138610$

Laurian, L., Crawford, J., Mason, G., Erickson, N., Kouwenhoven, P., Day, M. and Beattie, L, (2010) Evaluating the Outcomes of Plans. Environment and Planning B 37(4): 740-757. https://www.waikato.ac.nz/php/research.php 2mode=show\&author $=417$

Laurian, L., Day, M., Backhurst, M., Berke, P., Ericksen, N., Crawford, J., Dixon, J. and 
Chapman, S. (2004) What Drives Plan Implementation? Plans, Planning Agencies and Developers. Journal of Environmental Planning and Management 47(4): 555-577. https://doi.org/10.1080/0964056042000243230

Lunt, N. and Davidson, C. (2003). Introduction: evaluate matters. In Lunt, N., Davidson, C. and Mc Kegg, K (eds) Evaluating Policy and Practice: A New Zealand Reader. Auckland: Pearson

Education. http://citeseerx.ist.psu.edu/viewdoc/download ? doi=10.1.1.360.8700\&rep=rep 1 \&type $=$ pdf

Metro Portland .(1994). The Nature of 2040: The region's 50-year plan for managing growth, http://www.oregonmetro.gov/sites/default/file s/natureof2040.pdf, accessed 14 August 2014.

Metro Vancouver. (2010). Metro Vancouver 2040: Shaping Our

Future, http://www.metrovancouver.org/planning/de velopment/strategy/RGSDocs/RGSAdoptedby GVRDBoardJuly292011.pdf , accessed 14 August 2014.

McDougall, A. and Maharaj, V. (2012). Closing the Gaps on the urban fringe of Australia capital cities: an investment worth making. Australian Planner 48(3): 131-140. https://doi.org/10.1080/07293682.2011.581244

Ministry for the Environment. (2012) Medium density housing: case study assessment methodology. Wellington: New Zealand Government.

https://www.mfe.govt.nz/publications/townsand-cities/medium-density-housing-case-studyassessment-methodology-0

Nikoofam, M., \& Mobaraki, A. (2016). In Pursuit of Sustainable Strategic Long-term Planning Throughout Meta-postmodernism as New Perspective of Stylistic Design. Contemporary Urban Affairs (JCUA), 1(1), 45-55. https://doi.org/10.25034/1761.1(1)45-55

Newman, P. and Kenworthy, J, (1989) Cities and Automobile Dependence. Aldershot: Gower. https://www.amazon.com/Cities-AutomobileDependence-Peter-Newman/dp/1857421035

Newman, P. and Kenworthy, J. (1999). Sustainability and Cities. Washington, DC: Island https://islandpress.org/books/sustainabilityand-cities

New Zealand Government, (2010). Spatial Planning Options for the Auckland Council, Cabinet paper from the Minister for the Economic Development and Environment, Wellington, New Zealand. http://www.mfe.govt.nz/more/cabinet-papersand-related-material-search/cabinetpapers/auckland-governance-reform/spatial
North Shore City Council (2003) North Shore City District Plan. Auckland: North Shore City Council.

https://www.aucklandcouncil.govt.nz/plansprojects-policies-reports-bylaws/our-plansstrategies/district-and-regional-plans/districtplans/north-shore-district-plan/Pages/northshore-district-plan-text.aspx

Phan, T., Peterson, J., and Chandra, S. (2009). Residential Intensification in a suburban fringe local government area, Casey, Melbourne Metropolitan area, Australia. Australasian Journal of Regional Studies 15(1): 81-100. https://www.researchgate.net/publication/255 650342_Residential_intensification_on_a_suburb an fringe local government area in the Mel bourne_Metropolitan_Area_Australia

Quastel, N., Moos, M. and Lynch, N. (2012). Sustainabilty-as-Density and the Return of the Social: The Case of Vancouver, British Columbia. Urban Geography 33(7): 1055-1084. https://doi.org/10.2747/0272-3638.33.7.1055

Randolph, B. (2006) Delivering the compact city in Australia: current treads and future implications. Urban Policy and Research 24(4): 473-490. https://doi.org/10.1080/08111140601035259

UK Government .(2009). World Class Places: The Government's Strategy for Improving Quality of Place, London: Department for Communities and Local Government. http://www.veiligontwerp-beheer.nl/publicaties/world-classplaces-the-government2019s-strategy-forimproving-quality-of-place/view

Waldner, L. (2008) Regional plans, local fates? How spatially restrictive regional policies influence county policy and regulations. Environment and Planning B: Planning and Design $35(4)$ : $679 \quad-\quad 700$. https://doi.org/10.1068/b33061

Wiles, J.L, Rosenberg, M.W. and Kearns, R.A. (2005), Narrative analysis as a strategy for understanding interview talk in geograohic research, Area, 37 (1), 89-99. https://doi.org/10.1111/j.14754762.2005.00608.x

Woodcock, I., Dovey, K., Wollan, S., and Robertson, I. (2011) Speculation and Resistance: Constraints on Compact City Policy Implications in Melbourne. Urban Policy and Research 29(4): 343-362. https://doi.org/10.1080/08111146.2011.581335 